\title{
Study on Vertical Welding Experiment for General SHS Welding Rods
}

\author{
Liu Haodong* \\ Aerial Mechanical Department \\ Naval Aeronautical and Astronautical University \\ Qingdao, China \\ e-mail: mdlhd@sina.com \\ * Corresponding Author \\ Cui Aiyong \\ Aerial Mechanical Department \\ Naval Aeronautical and Astronautical University \\ Qingdao, China \\ e-mail: cuiaiyonghaijun@163.com
}

\author{
Hu Fangyou \\ Aerial Mechanical Department \\ Naval Aeronautical and Astronautical University \\ Qingdao, China \\ e-mail: navy_hd@sina.com \\ Wang Xiaofei \\ Department of control \\ Naval Aeronautical and Astronautical University \\ Qingdao, China \\ e-mail: cody05@163.com
}

\begin{abstract}
There were vertical welding was operated with general SHS welding rods based on Fe-base which was developed by our organization in this paper. Not only experimental phenomenon in the process of welding include form of molten bath and flow of fusion solder, but also experimental phenomenon after welding include macrograph form of welded seam and slag form were observed and analyzed. The currently main problems for manual SHS vertical welding were analyzed, and the reasons which caused the above phenomenon was discussed from two aspects of macroscopic and microscopic. The text summary finally points out the significance and function of the failure test. The important significance and impact for the experiment were pointed out in the end of the paper.
\end{abstract}

Keywords-SHS; manual welding; vertical welding; experiment; welding rods

\section{INTRODUCTION}

Manual self-propagating welding (MSHSW) was a new welding method based on self-propagating fusion, which have significant advantages that no need for external energy and equipment, carrying convenient, simple operation and can be used individual and in fast common use, the method welding method is an ideal welding in emergency repair, and which has a broad application prospect. The welding materials were combustion rods, which was the key to realize manual selfpropagating high-temperature welding [1-4]. Currently, manual self-propagating high-temperature welding rods can realize weld of many metallic materials such as low carbon steel, medium carbon steel, alloy steel, stainless steel, copper alloy and so on, the welding joints have good comprehensive mechanical properties, which tensile strength up to $400 \mathrm{MPa}$ approximately [5-7].

However, there were far high request for operators and welding technology and equipment because of the particularity of the MSHSW, which was a bottleneck problem for the technology further promotion and application in the field of emergency repair [8].
There were hardly any academic reports on MSHSW (especially the vertical welding) at home and abroad. Therefore general SHS welding rods based on Fe-base was used to weld Q235 low carbon steel welding material, the phenomenon in the vertical welding was analyzed from two aspects of welding process and welding rods formula. The theoretical and experimental foundation for MSHSW rods application more widely were established.

\section{EXPERIMENTAL MATERIALS AND METHODS}

\section{A. Experimental Materials}

The specification for general SHS welding rods based on Fe-base which was developed by our organization were $10 \mathrm{~mm}$ in diameter and $160 \mathrm{~mm}$ in length, and the mass fraction of each component in welding rods were shown in table I . The welded specimen materials were industrial Q235 steel, which specifications were $70 \mathrm{~mm} \times 35 \mathrm{~mm} \times 3$ $\mathrm{mm}$.

TABLE I. THE CHEMICAL COMPOSITIONS OF THE COMBUSTION WELDING RODS (W\%)

$\begin{array}{lllllll}\mathrm{CuO}+\mathrm{Al} & \mathrm{Fe}_{2} \mathrm{O}_{3}+\mathrm{Al} & \mathrm{CuO} & \mathrm{Cr}_{2} \mathrm{O}_{3} & \mathrm{MnFe} & \mathrm{FeSi} & \text { Others }\end{array}$

$\begin{array}{llllllll}62.5 & 19.2 & 8.3 & 2 & 1 & 5.2 & 1.8\end{array}$

\section{B. Experimental Methods}

The contrast experimental methods flat position welding and vertical position welding was designed, The two welding process parameters were shown in table II and III respectively.

TABLE II. The Process Parameters Of Flat Welding

\begin{tabular}{cccc}
\hline $\begin{array}{c}\text { Welding speed } \\
\boldsymbol{v}\left(\mathbf{m m} \cdot \mathbf{s}^{-1}\right)\end{array}$ & $\begin{array}{c}\text { Welding } \\
\text { angle } \boldsymbol{\theta}\left({ }^{\circ}\right)\end{array}$ & $\begin{array}{c}\text { Arc length } \\
\boldsymbol{a}(\mathbf{m m})\end{array}$ & $\begin{array}{c}\text { Preheat } \\
\text { condition }\end{array}$ \\
\hline $4-6$ & $80-90$ & $5-10$ & No preheating \\
\hline
\end{tabular}


TABLE III. The Process Parameters OF Vertical Position WELDING

\begin{tabular}{cccc}
\hline $\begin{array}{c}\text { Welding speed } \\
\boldsymbol{v}\left(\mathbf{m m} \cdot \mathbf{s}^{-1}\right)\end{array}$ & $\begin{array}{c}\text { Welding } \\
\text { angle } \boldsymbol{\theta}\left({ }^{\circ}\right)\end{array}$ & $\begin{array}{c}\text { Arc length } \\
\boldsymbol{a}(\mathbf{m m})\end{array}$ & $\begin{array}{c}\text { Preheat } \\
\text { condition }\end{array}$ \\
\hline $4-6$ & $60-70$ & $3-6$ & No preheating \\
\hline
\end{tabular}
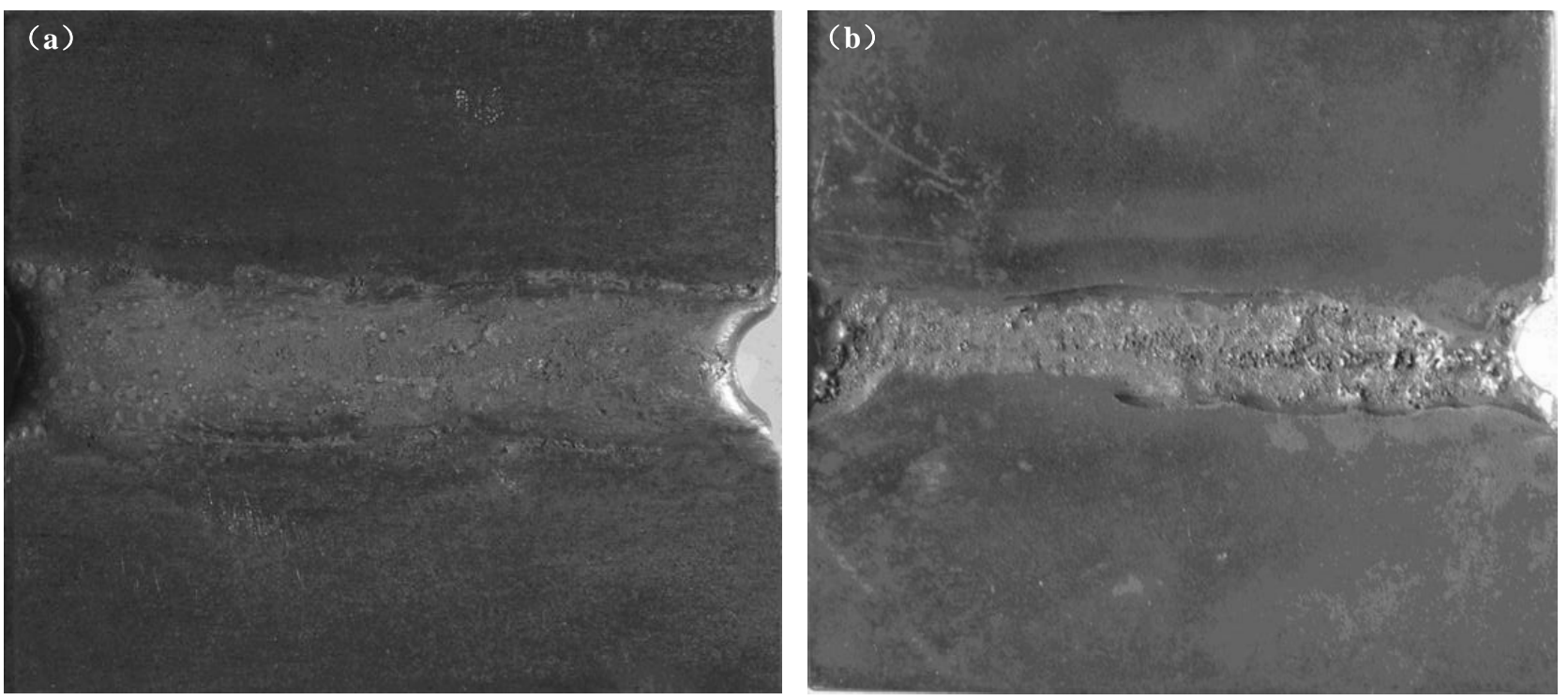

Figure 1. Sample of the flat position welding with butted plate: (a) front of the joint; (b) back of the joint

As shown in Fig .1. In flat position welding process, not only welding arc was stability and globular transfer was smooth and splash was little, but also molten pool was calm and the molten solder spreadability was ideal.

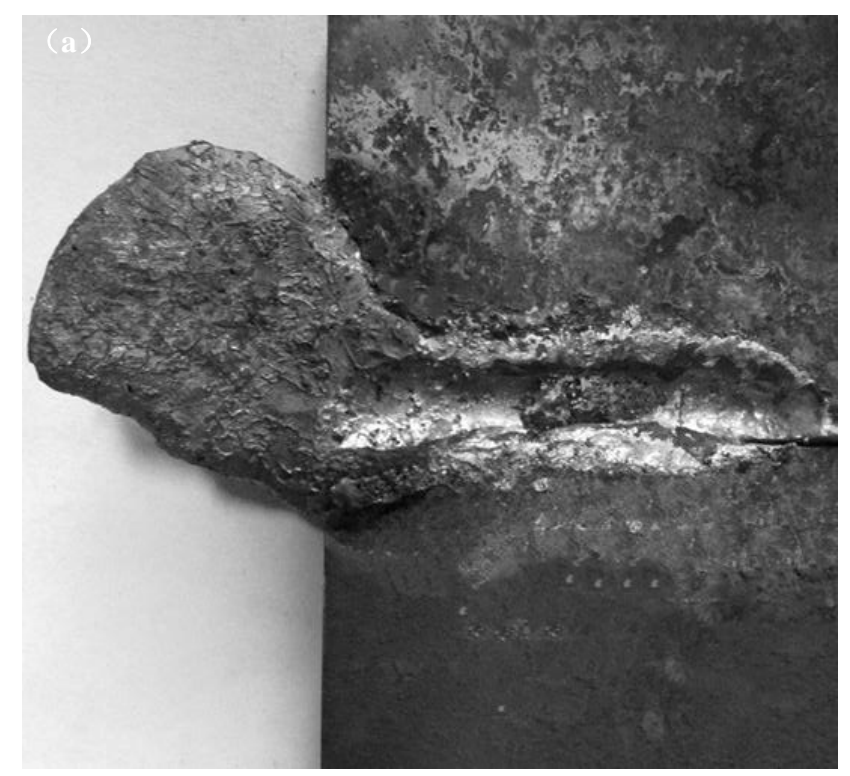

\section{RESULTS AND DISCUSSION}

\section{A. Experimental Results}

The weld joints morphology for flat position welding and vertical position welding were shown in Fig .1 and Fig .2 below respectively.

Meanwhile welding seam surface was level and metal fusion was in good condition and no obvious macro crack or blowhole defects such as inclusions, one-sided welding with back formation was realized [9].

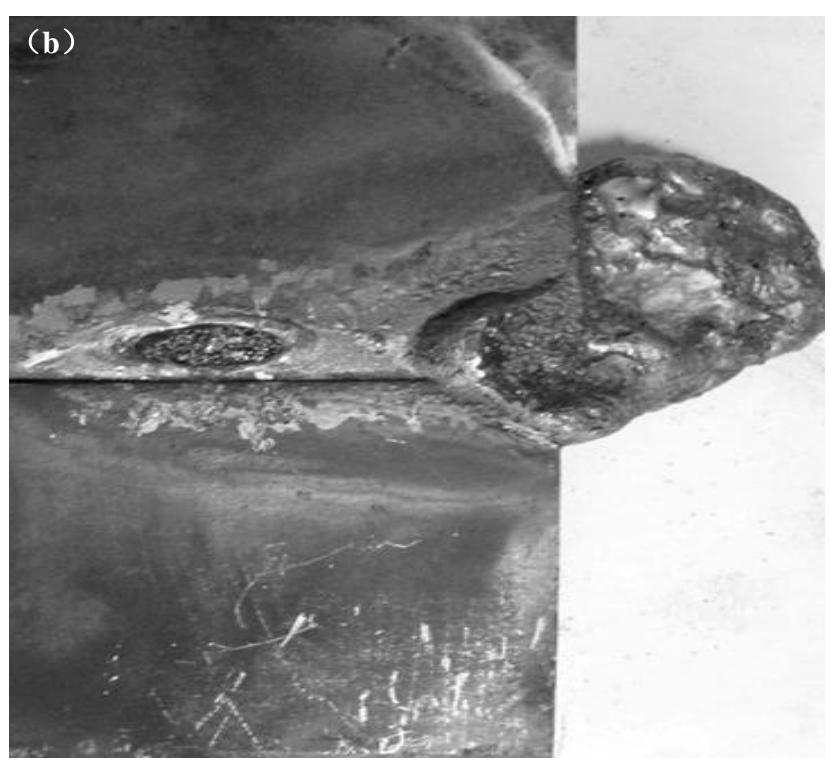



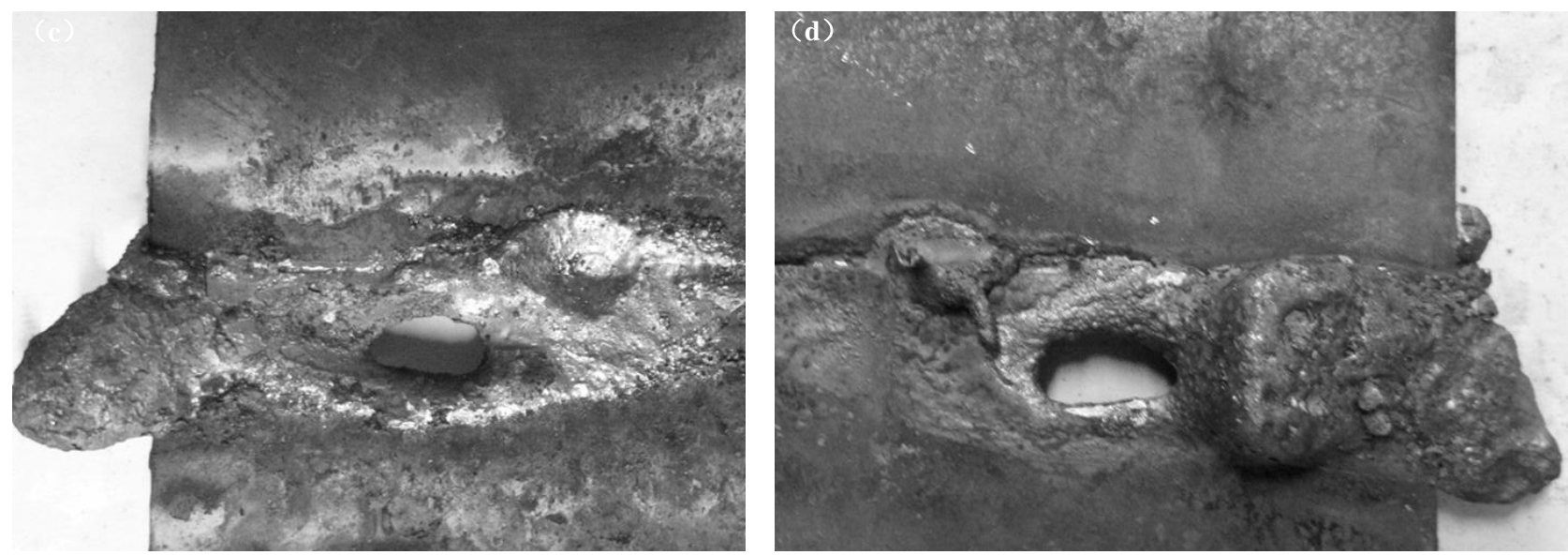

Figure 2. Sample of the vertical position welding with butted plate: (a) front of the joint for vertical up welding; (b) back of the joint vertical up welding; (a) front of the joint for vertical down welding; (b) back of the joint vertical down welding

As shown in Fig .2, during the upwards welding process, the molten solder drip seriously in the effect of the gravity, the wetting and adhesion on the parent metal molten solder was poor, liquid metal drip along the base metal surface in spherical and accumulated in the lower part of weld joints, a large number of bare and wrapped by slag metal balls (as shown in Fig .3 (a), (b)) can be found after welding, combustion of welding arc was stable,

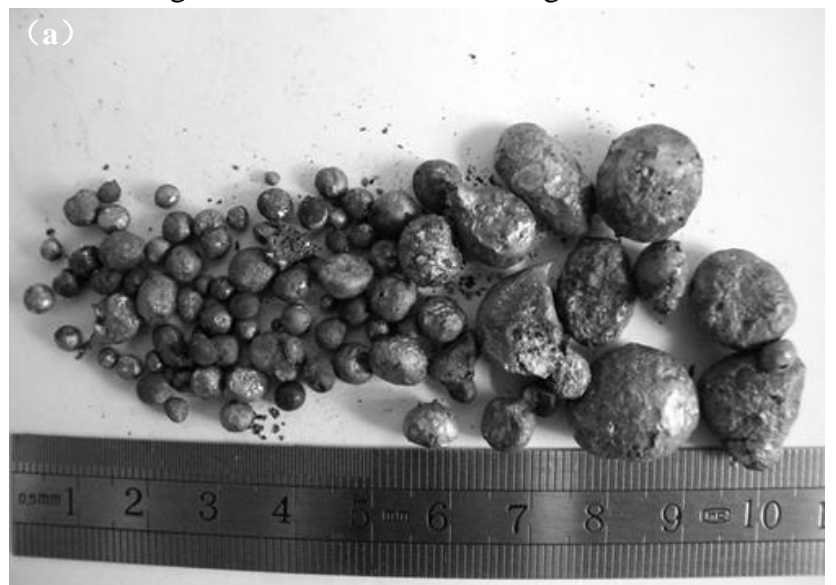

molten drops splash was small, and the formation of molten pool and advancing speed were instability, weld appearance was poor, there were macro welding groove along the weld and no weld metal above weld seam, the vast majority of the weld metal accumulated random in the bottom edge, and there was slag inclusions on the back of weld seam.

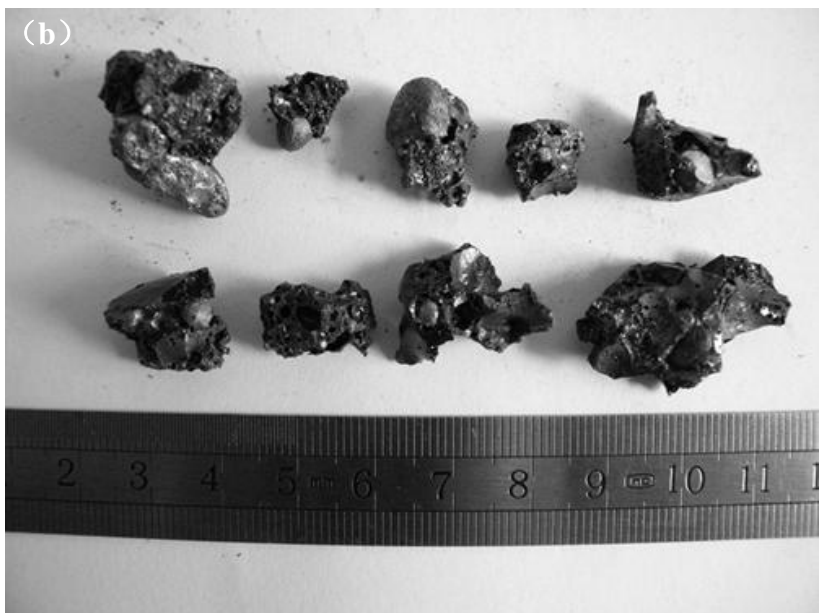

Figure 3. Slag of the vertical position welding: (a) metallic ball after vertical position welding; (b) metallic ball in the welding slag

\section{B. Mechanics Properties}

According to the criterion of GB/T2649-1989 and GB/T2653-1989 and GB/T3965-1995, the welded specimen were processed into the standard tensile and bending testing specimen, and the tensile and bending strength test were carried on in electronic universal testing machine [10]. Welding joints have good comprehensive mechanical properties, which tensile strength was up to $410 \mathrm{MPa}$ and the bending strength was up to $1126 \mathrm{MPa}$ and impact toughness was up to $32 \mathrm{~J}$, the mechanical properties fully meet the welding joints requirements for both battlefield and field emergency repair [11]; The vertical welding joints also were processed into the standard testing specimen according to the same methods, however due to the vertical welding joints were not truly effective connection, the welding joints fractured in the process of making standard testing specimen, therefore we can only rough estimated that tensile strength and bending strength and impact toughness were very low, so the actual vertical welding joints have no practical application value.

\section{Results Discussion}

In the vertical position welding process, the reasons lead to the phenomenon that the molten solder drips seriously were mainly two aspects of macroscopic and microscopic.

At the macro aspects, the welding rods cannot produce enough gas because of no specific gasification agent. At the micro aspects, because the surface tension of the molten solder on the parent metal was large, leading to the wetting adhesion and spreadability of the molten solder were poor, therefore the molten solder in the molten pool flew easily under gravity.

After completion of welding, we can analyzed by observing the vertical up welding specimen that macro 
welding groove along the weld bead show that the base metal has been melted by the welding electrode, but the appearance of weld was poor, and there was no weld metal adhere to weld bead, which showed that as observed phenomena in the process of welding the molten metal drip in the effect of gravity, and did not form a good weld filler, meanwhile caused a most lacked of weld metal under random accumulation in the welding bottom edge, and make the lower excess heat caused a partial burn through at the bottom of the weldment. There were large inclusions on the back of weldment, and most of the inclusions was slag composition, at the same time, the existence of a small amount of weld metal showed that slag melting point was higher, and there was no enough time to come to the upper molten solder and condensing spread out in the base metal surface, the presence of metal in slag shows that the separation effect is not ideal. For the phenomenon that vertical downward welding in upper bead is not weld formation and the upper part of the lack of penetration, the lowest in base metal welding wear, the reason can be interpreted that wetting of molten solder and adhesion were poor, and the block effect for molten metal of the slag and welding arc blow force was poor, the molten metal drip along the weld beam, leading to the heat of upper weldment was insufficient. As welds continues, the molten metal drip to the welding specimen middle part, which can be look as to high temperature preheat for the downmost weldment, therefore there was weld penetration in the effect of welding arc heat and solder heat.

\section{CONCLUSIONS}

In addition to the principle of self-propagating welding particularity, the reasons that lead to poor vertical welding effect with general Fe-base combustion welding rods welding were two aspects comprehensive factors including macroscopic and microscopic.

The above problems were resolved in a certain degree through improving welding process and welding rods components.

\section{ACKNOWLEDGMENT}

This work was financially supported by the Natural Science Foundation of China (51505491) and the Innovation Program of Naval Aeronautical and Astronautical University (20121009).

\section{REFERENCES}

[1] Xin Wentong, Ma Shining, Li Zhizun, Li Baofeng and Hu Junzhi, "Technology of manual SHS welding," Hot Working Technology, vol. 36, Dec. 2007, pp. 18-20.

[2] Zhang Baoyuan, Xin Wentong, Li Zhizun, "Analysis on properties and microstructure of welded joints by manual SHS welding," Hot Working Technology, vol. 36, Aug. 2007, pp. 16-18, doi:10.3969/j.issn.1001-3814.2007.15.006.

[3] Wu Yongsheng, Wang Jianjiang, Xin Wentong, Qu Lifeng and Chen Xueli, "Slag inclusion in joints of vertical weld by plus combustion welding rod," Electric Welding Machine, vol. 44, Feb. 2014, pp. 67-69.

[4] Liu Haodong, Zhang Long, Xin Wentong, Wang Jianjiang, Wu Yongsheng and Wang Xiaojing, "Ingredient optimization of manual SHS welding rod applicable for vertical welding base on uniform method," Materials Review, vol. 26, Apr. 2012, pp. 12512, doi:10.3969/j.issn.1005-023X.2012.08.032.

[5] Xin Wentong. Research on SHS welding mechanism of equment metal material[D]. Beijing: Academy of Armored Forces Engineering, 2010: 75-77.

[6] Xin Wentong, Ma Shining, Li Zhizun and YaoJungang, "Effect of Cr Content on Microstructure and Properties of Manual SHS Welding," Hot Working Technology, vol. 17, Sept. 2009, pp. 5-7, doi:10.3969/j.issn.1001-3814.2009.17.002.

[7] Wu Yongsheng, Wang Jianjiang, Xin Wentong, and Qu Lifeng, "Tensile strength and fracture microstructure of Q235 steel joints prepared by manual self-propagating vertical weld," Materials Science and Engineering of Powder Metallurgy, vol. 18, Dec. 2013, pp. 893-898, doi:10.3969/j.issn.1673-0224.2013.06.020.

[8] Liu Haodong, Zhang Long, Wang Jianjiang and Wu Yongsheng, "Investigation of Vertical Welding Technics and Discussion on Vertical Welding of Manual SHS Welding," Hot Working Technology, vol. 40, Apr. 2010, pp. 16-20.

[9] Li Baofeng, Xin Wentong, Li Zhizun and Zhu Haihua, “A new Welding Technology used in lash-up repair," Journal of modern manufacture engineering, May. 2008, pp. 107-109.

[10] Li Jianping, Shi Quan, Gan Maozhi. Theory and application of arming lash-up repair in battlefield[M]. Beijing: weapon industry press, 2000. 